\title{
Higher Education Institutions in the Knowledge Triangle
}

\author{
Mario Cervantes \\ Senior Economist, Country Studies and Outlook Division, Directorate for Science, Technology and Industry, \\ mario.cervantes@oecd.org
}

Organisation for Economic Co-operation and Development (OECD), 2, rue Andre Pascal 75775 Paris Cedex 16 France.

\begin{abstract}
$\mathrm{T}$
his paper discusses some of the policy issues and best practices aimed at enhancing HEIs performance and improving their impact on society and the economy within the knowledge triangle. The knowledge triangle concept aims at exploring ways to better align and integrate the research, education and innovation functions of HEIs. The paper describes the contents of the knowledge triangle, HEI performance through the lens of this concept, policies to promote the knowledge triangle in HEIs, as well as potential contradictions in relation to other knowledge producers, such as public research centers and companies.
\end{abstract}

Abstract

Keywords: knowledge triangle; research; education; innovation; third mission; regional ecosystems; placebased policy; higher education institutions (HEIs); universities; knowledge transfer.
The conclusion is that there is no single model for universities and the knowledge triangle. This is due to the country-specific peculiarities of educational systems, diversity within HEIs themselves and the functions they perform, as well as the specific features of regional ecosystems. Accordingly, the key to the efficiency of the knowledge triangle tools is their place-based adjustment. In order to achieve a tangible contribution of universities to the development of regional and local innovation, it is necessary to ensure complementarities and a balance between their missions.
Citation: Cervantes M. (2017) Higher Education Institutions in the Knowledge Triangle. Foresight and STI Governance, vol. 11, no 2, pp. 27-42.

DOI: 10.17323/2500-2597.2017.2.27.42 
$\mathrm{H}$ igher education and public research systems are undergoing a system-wide transformation in OECD countries [OECD, 2016]. Decades of policy reforms in tertiary education, public research and innovation policy intersect, and sometimes clash, in the context of higher education institutions.

On the research side, global competition for scientific excellence and decades of disengagement from basic research on the part of companies has made HEIs the locus of national public research efforts. The mergers and restructuring of public research organisations (PROs) - many of which are focused on "mission-oriented" research - has also benefited HEIs, which have absorbed some PRO institutes. Denmark for example decided to integrate several government research institutions into its universities. In the UK as well, some institutes have also been absorbed by universities [OECD, 2011; Ponchek, 2016; Vargiu, 2014]. Project-based research funding schemes have also increased in recent years as a way for governments to try to steer research priorities at HEIs and improve accountability. Specialised centres of competencies/excellence have also been financed and positioned at HEIs in order to capitalise on existing strengths or to explore new areas and increase institutional differentiation.

On the education side, the conversion or upgrading of technical colleges into universities or universities of applied sciences has also expanded the higher education landscape and forced institutions to better differentiate themselves and their education market offerings. Meanwhile, firm-based activities and structures have evolved considerably in recent years (e.g., the rise of open innovation and global value chains, big data and dis-intermediation), creating new demands on HEIs in terms of talent and skilled graduates, but also in terms of the industry-relevant research to improve firm competitiveness [Gackstatter et al., 2014; Gokhberg et al., 2016; Meissner et al., 2016].

On the innovation side, innovation policy has become a networked and decentralised government policy where innovation agencies or regional development bodies take on a greater role. Collaboration with public research, whether in the form of the science-push transfer of public research results to industry or demand-pull initiatives such as through public-private partnerships, has become the dominant discourse and a key focus of innovation policies. Even fiscal policies to support business increasingly target R\&D collaboration between public research and large and small firms. Furthermore, the delegation of competences and innovation policies to agencies and regions has naturally brought innovation policies closer to the world of higher education policies, which has long had a strong regional or place-based dimension.

Entrepreneurship policies have also entered the fray as HEIs are being encouraged not only to educate and train entrepreneurs, but also to sponsor entrepreneurial activities on campus. In Norway, for example, all HEIs have entrepreneurship education, either as a special study programme or as a course embedded in other programmes [Borlaug et al., 2016]. This is a rational development as Schumpeterian entrepreneurship is the main channel through which knowledge developed at HEIs finds its way into innovation [Carayannis et al., 2015; Proskuryakova et al., 2015]. This can be considered a consequence of the concept of the "entrepreneurial university" put forward in the early 2000s when Etzkowitz and Leydesdorff [Etzkowitz, Leydesdorff, 2000] described the Triple Helix and concluded that the university model is changing towards an entrepreneurial model, which stresses the application and exploitation of research.

However, if much of the support for basic research and tertiary education that is performed by HEIs comes from public coffers, government support to business $R \& D$ has also increased in the period following the financial crisis such that the amount of public investment that in some way or another is channelled through HEIs represents several percentage points of GDP: in 2011, 1.6\% of GDP on average was dedicated to tertiary education institutions in the OECD in 2011 and $0.44 \%$ of GDP was spent on higher education R\&D (HERD). Public support for business innovation that involves HEIs takes various forms such as:

- tax credits for companies collaborating with universities

- Small Business Innovation (SBIR)-type of schemes

- industry $\mathrm{PhD}$ programmes and student internships at companies

- innovation vouchers to help small firms wishing to purchase university research or consulting services, often funded by regional authorities.

The amount or proportion of this stream of public support to innovation is unmeasured, but anecdotal evidence suggests that it is important to certain HEIs and to certain regions/countries.

For these reasons alone, it is important to understand the following questions. How do HEIs position themselves within the KT and what are the implications for national innovation policies? To what extent do funding and governance policies support KT activities? Are "silo" funding streams for research, education and innovation a barrier for KT activities and what can be done to overcome this? How should one design policies for HEIs in countries with different industrial and higher education structures? Are there ways to link HEIs effectively with regional enterprise and social actors? And finally, what are the new institutional models and good practices to overcome these obstacles? These are some of the questions that the article aims to answer. 


\section{Importance of HEIs for innovation, education and research}

HEIs matter for innovation for several reasons. First, HEIs play a mediating role between capital and labour in economic growth. HEIs train and develop productive human capital through teaching activities. Human capital accumulation has been an important driving force behind aggregate economic growth [OECD, 2008]. Compulsory education remains the first channel for human capital accumulation, especially in developing and emerging economies. In advanced countries, however, which are closer to the technological frontier, investment in tertiary education provides high social returns from the accumulation of knowledge capital and spillovers in the economy, which justify the fact that governments directly or indirectly subsidise $70 \%$ of tertiary education in OECD countries. Over the past decades, OECD countries have supported the increasing participation of students in tertiary education, mainly at universities. Of course, there are also high lifetime private returns from tertiary education which increases demand for HEIs. There are also distributional effects on equity and income inequality that arise from access or lack thereof to higher education. These effects, however, are outside the scope of this paper, which focuses on the contribution of HEIs to innovation systems.

The second reason HEIs matter is that they carry out a large share of public research, both basic and applied. A properly organised higher education system can increase the efficiency of research activities, which in turn increases the stock of knowledge capital - as distinct from human capital — which is the basis for technological progress. In endogenous growth theories, knowledge capital is suggested to have a greater potential for constant, rather than diminishing, returns, thus providing a mechanism for permanent growth effects from increases in capital. In these models, HEIs are part of the knowledgeproducing sector, the other part being R\&D-intensive firms. In many OECD countries, half of the national efforts concerning research are carried out by HEIs and public research organisations (HEIs). However, one fundamental difference between the knowledge capital created in HEIs and the knowledge capital created in firms are the incentives. Firms have the incentive to invest in research when the outcomes of the $\mathrm{R} \& \mathrm{D}$ can generate market power (through intellectual property rights, IPRs) and higher profits.

The third reason that HEIs matter is that they contribute to local economic development through so-called "third mission" activities or "community engagement". The third mission is a broad concept that groups together the concepts of the entrepreneurial and commercial activities of HEIs, their social and cultural relevance, and knowledge transfer. The term is generally used in science and innovation policy to capture knowledge exchange activities; in the education community, the term is used more frequently to refer to the role that HEIs play within their community. This concept is not new; both knowledge exchange and community engagement are long-standing characteristics of HEIs in most OECD countries. However, during the dual move towards increased autonomy and accountability for HEIs in most countries, many countries have acted to strengthen and formalise the social and knowledge transfer role of HEIs. Thirdmission activities include, but are not limited to:

- informal engagement with industry;

- consulting and advisory activities of academics;

- inputs for public policymaking;

- support for entrepreneurship skills among students and researchers;

- exploitation of the results of research activity;

- the creation of links between universities and vocational colleges;

- contribution to community interaction (e.g., classes for non-students).

Goddard and Puukka [Goddard, Puukka, 2015] note that many third-mission activities are often confined to the periphery of management and leadership of the higher education system. The notion of a third mission varies across countries, but in many cases, it is an unfunded mandate and expectation placed on HEIs and, to a lesser extent, on PROs. While the traditional core focus of leadership of research universities is on research excellence, teaching (and the appearance of both in published rankings), and third-mission targets mandated by central and regional governments, many other activities do not have the same incentives. The drivers and incentives for teaching, research and external engagement are often unrelated and competing.

The fourth reason that HEIs matter has to do with their contribution to local economic development. Knowledge is created locally and while some of this knowledge can be codified and diffused globally, much of the tacit knowledge generated by students, faculty and firms is "sticky" and remains so that the spillovers are localised. Furthermore, highly skilled graduates contribute to the quality of the local workforce. HEIs are themselves large employers and provide services to companies and public agencies (e.g., university hospitals) in the regions. They are also factors of "attractiveness" for national and local economic development strategies, drawing in faculty, students and also companies from outside regions or countries to co-locate around universities in order to obtain access to the talent and cutting-edge research.

Finally, and as a result of the above functions, HEIs have become central actors in innovation systems. The national innovation systems theory considers HEIs key actors in the performance of national innovation systems given their important functions. However, HEIs are also under tremendous pressure from governments and other stakeholders to transform themselves in order to cope with the realities 


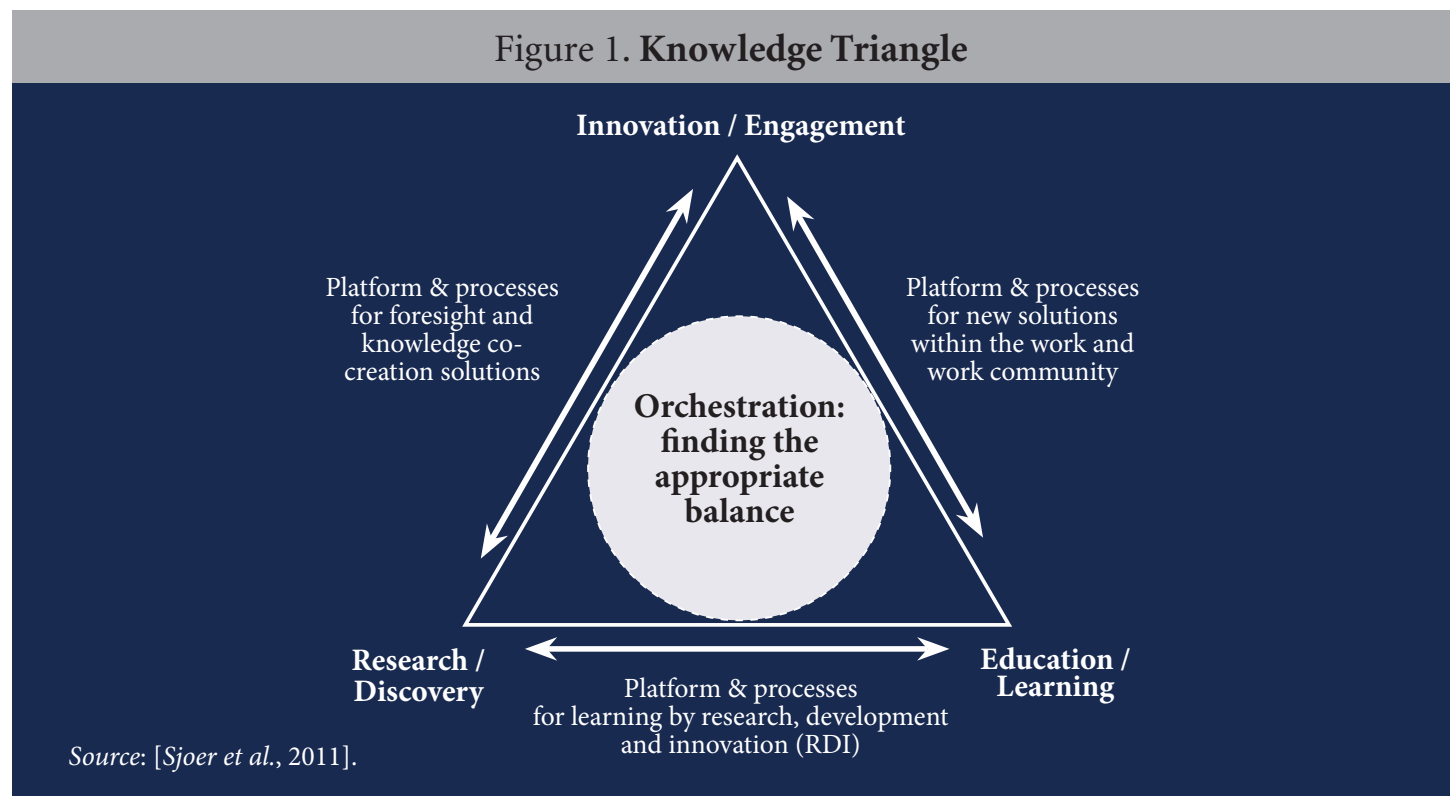

of the globalisation of higher education and research, the expansion of tertiary education and the increasing demands for equity and access. HEIs also continue to face budgetary pressures in light of the decentralisation of higher education funding in many countries as well as the competition for research funding. The transition to the digital age in education (e.g., Massive Open Online Courses - MOOCs) is another challenge, but also an opportunity for HEIs. Indeed, research and education ministries in many OECD countries are looking towards the "knowledge triangle" as a framework to help HEIs improve their impact on society and the economy.

\section{What is the Knowledge Triangle?}

Traditionally, the linking of research to innovation has been encouraged by governments and industry. In addition, in HEIs with a Humboldtian tradition (e.g. in Germany, the US and Northern Europe) the linking of research with education has been well established since the $19^{\text {th }}$ century. However, this link has continued to evolve as governments channel greater amounts of research funding toward HEIs. In contrast, the links between education and innovation have been less the focus of national policymakers or institutional leaders until recently.

The knowledge triangle is a policy framework that stresses the need for an integrated approach to research, innovation and education policy with a focus on HEIs as knowledge creating institutions. It was conceived in 2000 as part of the European Union's Lisbon Strategy in response to a lack of innovation and entrepreneurial culture in research and higher education; a lack of investment, in particular private investment, in research and development (R\&D); and the difficulty European countries face in translating $\mathrm{R} \& \mathrm{D}$ results into commercial opportunities.

The knowledge triangle postulates that knowledge generated by HEIs is the result of three core elements (the vertices) which are: i) education; ii) research and iii) innovation. Each of these elements influences the others. These bi-directional or circularly-caused knowledge flows between the three core elements of the knowledge building process constitute the Knowledge Triangle (Figure 1).

At the centre of the triangle, orchestration tools, understood as the tools to mobilize and integrate resources to create value for the members of the knowledge network [Wallis, 2006], are set-up in order to provide an overall articulation and achieve balance between the different components of the knowledge creation system [Sjoer et al., 2011]. In practical terms, they typically correspond to multi-stakeholder platforms (virtual, in-person and/or mixed), bringing together actors from the public, private and academic sectors around joint research and educational collaboration. The model stresses the equal importance of each of the elements of the knowledge creation process (an equilateral triangle) as well as on the need for an integrated, holistic approach that focuses not only on each of the single vertices, but especially on the two- and three-way interactions between education, research and innovation [Markkula, 2013]. In such interactions, there are positive externalities that spill over to each dimension [Hervás Soriano, Mulatero, 2010]. Each of the linkages in the triangle can be strengthened by means of platforms and processes that build bridges between education, research and innovation, thus facilitating the circulation of knowledge [Sjoer et al., 2011].

The novelty of the knowledge triangle concept, however, is that it draws attention to the contribution of education to research and that of education to innovation. Traditionally, policy has been concerned 
with the contribution of education to labour market success or the training of highly qualified graduates for research activities. With regard to the innovation function, most policies have focused on increasing the contributions of research to innovation through legislative reforms (e.g., the Bayh Dole Act) and the establishment of technology transfer offices (TTO) or other interfaces between research and innovation at firms.

\section{The link between education and research}

In terms of the linkages between education and research, the importance of skilled human capital for successful R\&D activities has long been internalised by science and research policies. Currently, many countries have science development policies based on a combination of postgraduate training, scientific (fundamental/basic and applied) research funding and advanced human capital insertion programmes. The current financial pressure on HEIs has, however, increased concerns and interest in the cost-benefits of such instruments.

\section{The relationship between $R \& D$ and innovation}

The other most policy-dominant side of the KT is the relationship between R\&D and innovation. The poor performance of innovation systems in turning R\&D efforts into innovations has motivated the implementation of a wide range of policy instruments for increasing the transfer of knowledge from universities to the productive sector. Some initiatives include: i) legislative reforms (the Bayh Dole Act), ii) public-private partnerships; iii) university-industry research contracts; iv) intellectual property rights (IPR); v) university spin-offs; vi) knowledge transfer offices; vii) business incubators viii) labour and student mobility; ix) consultancy activities; $\mathrm{x}$ ) conferences and xi) electronic collaboration platforms.

Geuna and Muscio [Geuna, Muscio, 2009] provide a comprehensive critical analysis of the current approaches to and mechanisms for the institutionalisation of knowledge transfers from academia to the productive sector in Europe and the US. After 30 years of experimentation in knowledge transfer policies, the authors conclude that there are more failures than successes, largely due to the incapacity of knowledge transfer policies to manage the trade-offs between the university's more traditional roles of teaching and knowledge generation with the increasing pressures for greater knowledge transfer. Some problems identified by the authors include the partially tacit nature of knowledge (not easy to transfer), the costs of network building and the difficulty of pricing knowledge. As pointed out by Hervás Soriano and Mulatero [Hervás Soriano, Mulatero, 2010], despite the fact that innovation can increase the efficiency and scope of R\&D activities, innovation policies still suffer from a unidirectional approach going from research to innovation, rather than from innovation to research or education and then back into innovation.

\section{The link between innovation and education}

Finally, in terms of the link between innovation and education, the KT perspective is interesting. Two aspects emerge as critical. In first place, the push to develop an entrepreneurial attitude among students has motivated a range of entrepreneurship education programmes [Oosterbeek et al., 2010]. Second, there has been an effort to adapt educational programmes to meet the needs of the productive sector or at least to involve industry on university boards. Although there are successful examples of universities that have succeeded in engaging with industry, the complex governance of the HEIs and entire higher education systems is a barrier in many cases [Maasen, Stansaker, 2011]. Yet, it is possible to find some cases that service as interesting examples of HEIs that have internalised the KT principles in their educational and business models. Some examples include the Aalto University [Markkula, 2013; Pirttivara, 2013] or the Catholic University of Leuven (KU Leuven) in Belgium [Van Petegen, 2013]. The particular initiatives undertaken by universities and public authorities are varied, including:

- The Living Labs model in Laurea University of Applied Sciences (Finland) [Hirvikoski, 2013]

- Tailor-made Continuing Engineering Education (CEE) programmes at Delft University (the Netherlands) and Aalborg University (Denmark) [Sjoer et al., 2013]

- Life-long learning programmes at KU Leuven (Belgium) [Van Petegen, 2013]

- The Aalto Camp for Societal Innovation (ACSI) of Aalto University (Finland) [Pirttivaara, 2013]

- Ecosystem networks in the Netherlands such as Brainport and Twente, which promote the knowledge triangle from a place-based perspective [Stam et al., 2016].

Again, we know very little about the reverse relationship, from innovation to education. In this regard, KT policies have been limited to the promotion of some innovations (mainly ICT's) for educational purposes [Hervás Soriano, Mulatero, 2010]. The knowledge triangle concept calls for an articulated approach based on both strengthening education, research and innovation, but above and beyond that, on reinforcing the interactions and positive externalities that are established between them. Thus, it implies a departure from the traditional view of knowledge production as a linear and sequential process and instead calls for a more systemic approach to research, education and innovation policies.

While its comprehensive focus makes the KT an appealing framework for policies aimed linking knowledge creation to innovation, it provides limited insights on the specific ways such interactions 
unfold and on how they should be governed. This is because of the diversity of countries' economic structures and the roles HEIs play in various countries. This suggests there is no single model to which countries should aspire.

\section{HEI performance in the context of the knowledge triangle}

Higher education systems vary widely across countries. The position and structure of HEIs is closely linked to long-term cultural and historical factors in different countries [Hartl et al., 2014]. While HEIs broadly perform the same role across different countries, their perceived cultural and historical significance varies. In some countries, HEIs have historically been very close to the state; in others, they have tended to be more independent and subject to competition. This context is likely to affect the characteristics and activities of HEIs across countries, as well as the collaboration activities they form. For instance, research is embedded into the mission of the HEIs in some countries, whereas in others it is a more recent activity of the sector. Higher education systems also vary in the degree of government intervention. Even in market-based education systems, the state normally intervenes and regulates to ensure quality and to set standards. In addition, through its role as a key funder of research in most countries, the state maintains some influence over research practices, as well as being a major source of incentives for HEIs. However, the levels of government oversight vary significantly across countries and, as a result, institutions have different levels of accountability and freedom to decide their own practices. Autonomy in higher education can take many forms. Decision-making and revenue-raising autonomy differ from academic autonomy, meaning different actors within HEIs may experience different forms of independence.

\section{HEI diversity}

HEIs encompass a range of different types of institutions. A broad definition of HEIs includes not only universities but colleges, academies, institutes of applied sciences, professional institutes, trade schools, and other organisations awarding academic degrees or professional certifications [IPP, 2015a]. The balance between the different types and sizes of HEIs varies significantly between countries. Universities of applied sciences are a common feature of some higher education systems in Europe, but other countries only distinguish between university and other non-university institutions. Similar diversity can be seen when looking at countries in Asia [Altbach, Umaskoshi, 2004] and North America [Davies, Hammack, 2005]. In terms of their activities, diversity in the population of HEIs can be characterised as horizontal or vertical. Concerning education, horizontal diversity implies that different courses and institutions serve different objectives and different streams of students [OECD, 2008]. However, horizontal diversity also applies to research and knowledge exchange activities, for instance, based on the intended audience for research outputs [Daraio et al., 2011]. Vertical diversity implies some degree of hierarchy of institutions (e.g., between "elite" research universities and vocational colleges), either in terms of reputation, or often in terms of the rewards built into government policies on accreditation, autonomy and funding allocation. The degree of vertical HEI diversity depends greatly on national policies and practices.

Research activities and research quality are major elements of diversity and differentiation between HEIs. While almost all HEIs teach students, the extent of research activities varies considerably. There are more readily available measures for vertical differentiation in research activity. By contrast, measuring and comparing teaching quality and human capital at the higher education level can be problematic. Another common component of diversity among HEIs concerns their activities outside of education and research. Such activities are often referred to as the "third mission" of HEIs and include, but are not limited to: informal engagement with industry, consulting and advisory activities by academics, contribution to public policy, support for entrepreneurship skills among students and researchers, the exploitation of research activity, links between universities and vocational colleges, and the contribution to community engagement (e.g., classes for non-students). The intensity of these types of activity among HEIs also varies according to historical factors and national policies.

The concept of the mission of HEIs is not universally agreed-upon. As an alternative, Laredo [Laredo, 2007] proposes an alternative three "functions" of universities, all of which involve different ways of interacting with society: mass tertiary education; the professional training of specialists and research activities with close ties to non-academic actors; and conduct of fundamental research and the training of research personnel.

\section{Diversity within HEIs}

Another important dimension of diversity concerns differences within HEIs. In particular, different fields of study are associated with very different types of education, research and other activities. Faculties within the same institution often have their own budgets and sources of funding and, as a result, may form a variety of different types of external relationships. These differences can have institution-wide implications, depending on the degree of subject specialisation of the HEIs. In addition, academic freedom often means that researchers and staff within the same institution undertake a wide range of practices and hold a wide range of sometimes contradictory values. Diversity within HEIs raises a number of questions and challenges for the tools and strategies concerned with the knowledge triangle. 


\section{Funding}

One manifestation of this diversity is that the patterns of public and private expenditure on higher education vary greatly across countries. In many systems, HEIs are highly dependent on public financing. In others, private expenditure (including from tuition fees and non-public funding of R\&D) is a more prominent feature of higher education. In three of four OECD countries, which spend the highest proportion of national wealth on HEIs, private sources account for at least $65 \%$ of the total investment, whereas private sources account for only around 5\% for the fifth and sixth biggest spenders on higher education. There is also a regional element to expenditure patterns; in general, the proportion of private expenditure is higher in non-European countries. The share of private expenditure on tertiary institutions increased between 2000 and 2011 across OECD countries, and a number of countries substantially increased tuition fees for students during this period [OECD, 2008]. The general decline of public research funds has led to an increasing reliance on alternative sources of funding by universities (including the revenues from an increasing the number of students, consultancy activities, funding from non-profit organizations, etc.) [Geuna, Muscio, 2009].

A second important implication is a more targeted allocation of research funds to top-research universities [Massen, Stensaker, 2011]. A consequence of both concurrent trends would be the growing segmentation of the HEI market between teaching and research universities. While some authors have argued that such segmentation is actually efficient from a resource allocation point of view (e.g., [Aghion et al., 2009]), others claim that it may bring problems to the whole university system. Massen and Stensaker [Massen, Stensaker, 2011] for instance, argue that the university's market segmentation may lead to an undesired break between education and research, which undermines academic standards, particularly at the undergraduate level. According to the authors, the focus on knowledge transfer in current EU policy may accelerate the process.

A far less understood relationship is the reverse link, from research to education. Hervás Soriano and Fulvio Mulatero [Hervás Soriano, Mulatero, 2010] argue that a rapid update of university curricula to ensure they include recent results from research should be a natural process at universities, but in practice, it is curtailed by the "hysteresis" of higher education institutions. In any case, it is hard to find specific examples of policies aimed at increasing the feed-back from research to education from which one might draw some lessons.

\section{HEIs' role in national innovation systems varies across countries}

Given the diversity of HEIs at the system and institutional level, the roles of universities within national innovation systems depend on a range of factors. HEIs do not operate in isolation in science and innovation systems. Rather, they act alongside government research, public research organisations (PROs), various forms of innovation bridging institutions (technology transfer centres, incubators, etc.), and national intellectual property protection laws, the structure of which all vary across countries. In addition, a diverse set of knowledge sharing agreements, institutions, social relationships, networks and infrastructures grouped under the term knowledge networks and markets (KNMs) provide a number of critical services to firms, organisations and individuals to engage in the meaningful exchange of knowledge and associated rights [OECD, 2011].

The successful contribution of HEIs to innovation also requires a demand for the knowledge they produce, both from firms and the government sector. Indeed, many countries have policies to encourage firms to collaborate with universities or PRIs and use their research services [IPP, 2015b]. However, the nature of this demand depends on factors such as industry structure and specialisation - evidence suggests that most firms typically look for new solutions within their existing areas of expertise [Fagerberg, Godinho, 2005]. Variations in industry structure may, therefore, also have an influence on the role that HEIs play in national innovation systems. As a result, the place that HEIs occupy within national innovation systems can be argued to be inherently tied to long-term, structural economic factors in a path-dependent process [Mowery, Sampat, 2005]. Indeed, a recent OECD presentation [OECD, 2015] showed how some innovation systems are more HEI-dominated than others. Therefore, from an innovation system perspective, there is no single success model for HEIs or for the knowledge triangle. The "optimal" structure of institutions that support innovation is likely to vary across countries. Different types of institutions can equally contribute to innovation via their education, research and other activities, in conjunction with other actors, institutions and networks. For example, applied technological and clinical research often has the clearest links with industrial innovation, especially the measurable indicators of patents. Curi et al. [Curi et al., 2013] show that the efficiency of technology transfer offices positively depends on the size of the institution, the degree of science and engineering specialisation, and the amount of privatelyfunded R\&D activities. That said, HEIs specialising in fundamental science help provide the knowledge for applied sciences to operate at the knowledge frontier. Furthermore, small teaching-only institutions may play an important role in developing the technical, creative and managerial skills that contribute to innovation. Moreover, HEIs are part of international networks, meaning country systems may specialise in particular fields.

Well-functioning education, research and innovation systems may therefore rely on the contributions of different types of HEIs. Diversity and differentiation imply that HEIs cater to different audiences in 
their education, research and innovation activities. They are therefore subject to different expectations. The "reach" of an institution's activities is, therefore, another measure of diversity. Large leading research universities are connected to global scientific networks, whereas small colleges are often focused on the needs of their local communities.

\section{Diversity and the concentration on HEI performance}

Understanding the diverse contributions of universities to innovation is critical in the design of research policy [Bonaccorsi et al., 2014]. Statistics show that, in a sample of the US and a number European countries, a small number of large institutions are responsible for a significant share of higher education student enrollment. The concentration of research and innovation activities appears even more concentrated, however the concentration of activity is not homogenous across systems. National university systems include a large variety of institutions, with a few large institutions and a much larger number of small universities.

What are the advantages and disadvantages of concentration? This is a critical issue from a policy standpoint as government research support programmes often directly influence the extent of concentration. The fact that more money might go to the HEIs that are deemed the best according to certain criteria would mean that they would grow in line with their quality, generating a concentration of resources at the best performers. The initial descriptive evidence suggests that, on average, HEIs with a larger student enrollment do not receive clear advantages. In the United States, institutions that have larger student enrollment have higher graduation rates, on average, and those that conduct more research and engage more in innovation have higher graduation rates than those that do not. Howevwer, the best institutions are also attracting students with the highest test scores, and once taken into account, the correlation between enrollment and graduation rates is weakened. Possible advantages of the concentration of activities within a few universities would arise if there are gains in size. These may be economies of scale in university outcomes, i.e., if larger institutions can produce better outcomes relative to their resources compared to smaller institutions [Cohn et al., 1989]. Another possible advantage from concentrating resources in only some institutions is the economies of scope that arise if the production of one output improves that of another output or its quality. For instance, engaging intensively in research might support innovation or education outcomes [Chavas et al., 2012].

However, at a certain point, there could also be diseconomies of scale in education arising from factors such as overcrowding or low levels of personalised learning [Robertson, Bond, 2005]. Diseconomies of scale could also affect research and innovation activities. Moreover, engaging in one activity may negatively affect engagement in another activity as for instance, innovation activities that may negatively impact the quality of research.

\section{Policies to promote the knowledge triangle in HEIs}

\section{Governance, autonomy and competitive funding}

The central issue in the governance of the knowledge triangle is to understand where the responsibility for the knowledge triangle framework lies, which governmental and institutional actions and policies must be put into place so that the HEIs can link the different functions of institutions. A second issue is to determine what barriers are in place, impeding good governance between government and institutions as well as within institutions. Further, which governance arrangements are more conducive to high-quality KT interactions and overall impacts? What interesting lessons in terms of success or failure have emerged from the experience of institutions that have undertaken or adopted the KT approach?

National higher education policies have changed considerably over the past few years. In line with changes to cross-government public management processes towards a market orientation and efficiency, there have been a number of prominent efforts to modernise higher education for the knowledgebased society. One of the most significant trends has been a move towards greater autonomy for HEIs [Estermann et al., 2011], and more focus on competition between institutions for funds, students, staff and reputation. Institutional autonomy is an important ingredient for high performing universities. One issue that has been explored in the literature is the link between autonomy and third mission activities. Aghion and Howitt [Aghion, Howitt, 2007] find that the more autonomous institutions in the US and Europe are, the more successful they are in establishing formal and informal ties to industry and other organisations. Furthermore, autonomy appears to increase research universities' productivity and one sees that research universities are more useful in places closer to the frontier of science and discovery. However, the difference in productivity between autonomous and non-autonomous research universities is just as significant away from that frontier as it is close to it. The aforementioned authors postulate that this may be because autonomy allows a university to direct resources toward more productive research and researchers. Results for the US also convincingly demonstrate that more financial investments are translated into degrees at a higher rate at more autonomous universities.

Autonomy and competition can influence the incentives faced by HEIs in both positive and negative ways. Using data from international university rankings, Aghion et al. [Aghion et al., 2008] find that budget autonomy has a large impact on the research performance of universities, controlling for other factors, 
but other indicators of autonomy have no statistically significant effect. Increasing the competition for students (though a long-running feature of some systems) may increase incentives to improve student outcomes and employability. This could result in teaching practices and other training that are closely aligned to those valued by students or employers. However, competition can also take on more perverse forms, such as offering a wide range of ancillary services, grade inflation or attracting international feepaying students [Abbott, Doucouliagos, 2009], which have less clear benefits for education, research and innovation. Furthermore, competition is skewed by the nature of higher education as a "positional good" [Marginson, 2006].

Therefore, ensuring competition leads to socially beneficial changes is a challenge for the new accountability and governance mechanisms. The high degree of autonomy and strong traditions, especially within specific academic departments, can also be a barrier to greater engagement with industry and the broader community. One key finding is that autonomy also requires the creation of leadership and strong incentives (including financing) in transforming university missions and performance [Goddard, Puukka, 2008].

In case of institutional core funding, HEIs usually have a large degree of autonomy in deciding whom and what to fund. In contrast, research funds that are provided on a contractual basis by the government and industry often come with conditions that define the boundary of use. The extent to which governments place conditions on public funds is one of the most important issues for both policymakers and HEIs, as they may affect the governance of institutions and the behaviour of individuals at those institutions, as will be discussed later in this paper.

\section{Multilevel governance}

Increased autonomy from government has often been accompanied by increased formal accountability mechanisms. The influence of government policy on higher education has become increasingly indirect in nature. This trend has manifested itself in a variety of new multilevel governance systems for HEIs. There has been a general shift away from negotiated budgets for HEIs towards explicit performance agreements [Salmi, 2007]. In many countries, priority-based funding formulas for teaching have been introduced, which focus on labour force needs or performance measures such as graduation rates. Almost without exception, increased autonomy has been accompanied by more robust quality assurance mechanisms, which are overseen by a national agency [OECD, 2008]. The processes involve a mix of accreditation, assessment (or evaluation) and audit [IPP, 2015a].

\section{Competitive funding}

Competition for research funding, for example, has increased. There is evidence across the OECD of a relative shift away from core research (block) funding for institutions towards competitive projectbased funding [OECD, 2008; Poti, Reale, 2007]. However, block funding has become more common than itemised funding as a means of government financing of HEIs' teaching and administration tasks [OECD, 2008], although often by means of a formula based on quasi-competitive variables such as the number of students. These changes have been intensified by the massification of higher education and by global competition for researchers and students. More competitive funding systems are likely to affect the incentives of researchers. In the face of a more competitive environment, the purpose of HEIs has come into question. Many countries have witnessed the rise of HEIs as competitive, more business-like institutions with less easily defined missions [Marginson, Considine, 2000]. They have become hybrid institutions with both a public mission and a private one. These trends have given rise to terms such as "entrepreneurial universities" and "academic capitalism" [Bramwell, Wolfe, 2008]. Internal governance and institutional management has also changed. HEI leadership has moved towards an increasingly topdown model, where department heads and university presidents have greater management and coalitionbuilding responsibilities, and they have been given direct power over nominations and strategic focuses in education and research. The implicit contradictions between the private missions and public ones can have a bearing on research and education. Using data from university collective bargaining agreements in the United States, Rhoades [Rhoades, 1998] found that academics' autonomy with respect to activities such as designing curricula or introducing new instructional innovations was declining as university management became increasingly centralised.

Competition for students, funding and reputation may have pushed HEIs to broaden their activities beyond their traditional remit. There is evidence in some countries that university and non-university distinctions are blurring, with the latter group starting to conduct more academic research [Lepori, 2008]. This process is sometimes known as "academic drift". In the context of the massification of higher education and higher competition, and given sufficient flexibility, revenue-seeking universities also have an incentive to expand their role, for instance, by bringing in students that may otherwise have received vocational education. In this sense, HEIs have diversified their educational offerings in the face of competition. Indeed, whole new institutional models have arisen in response to the changing higher education environment [OECD, 2008]. Competition for students and researchers at the global level may encourage HEIs to become active players in international networks and seek ways to enhance their international reputation. 
Industry funding of HEIs

In the face of budgetary constraints faced by most countries, HEIs have changed their attitudes towards business as an additional source of funding, encouraged by reforms and government policies. Industry funding for HEIs varies across OECD countries. Data shows that industry is a more important funder of higher education R\&D (HERD) in some countries than others. In France and Japan, industry accounted for $2.7 \%$ of HERD in 2012, compared to $14 \%$ in Germany. Across OECD countries, the percentage of HERD financed by industry rose dramatically during the 1980s, but has been more stable since, declining after the start of the 2008 global financial crisis. One must note, however, that industry is not the only private source of funding for the activities of HEIs; non-profit foundations, philanthropic organisations and citizen initiatives (community funding, crowdfunding) are also sources of non-state funding for research and education. The drivers behind these trends are a topic of interest for the positioning of HEIs in the knowledge triangle.

The relationship between HEIs and industry is more crucial in some fields than they are in others. In the US, medical sciences and engineering departments receive much more funding from the business sector than other scientific fields. An empirical study of Italian universities found that departmental differences had an effect on the extent of engagement with industry. The study also found that private funding is more of a complement to public funding than a substitute [Mucio et al., 2013]. Furthermore, as industry funding is usually provided through contractual arrangements with explicit objectives and demands on research, the increasing role of industry in funding might have negative effects on the autonomy of research, and result in an increase in applied research relative to basic research. At the same time, the negative, neutral or positive effects may depend on the quality of basic research or the quality of researchers co-operating with industry. The industrial sector of the co-operating firm, its R\&D intensity or its human capital structure may also have an impact on changes in the area of public research.

A more general question is whether industry funding of higher education "R\&D" is the correct metric for assessing the impacts of university engagement with industry. As stated at the beginning of this paper, the relationship between HEIs and businesses has been focused on the research link, i.e., the $\mathrm{R} \& \mathrm{D}$ connection and therefore, the role of businesses funding higher education R\&D. The educational linkages between HEIs and industry may be a more fruitful area for studying the effects of industry and academic co-operation from the standpoint of the knowledge triangle.

Another issue concerns the nature of the links between HEIs and industry and the effects these may have on research areas. Industry-science relations are often stronger in some fields (e.g., engineering, ICTs, life science) than others (e.g., sociology, political science). Indeed, research has found that departmental differences have an effect on the extent of Italian HEIs' engagement with third party funding [Bonaccorsi et al., 2014]. In the US, medical sciences and engineering departments receive much more funding from the business sector than other academic fields. At the same time, as industry funding is usually channelled through contractual agreements with explicit objectives, there is a risk that industry funding could reduce the autonomy of institutions and result in shifting public research towards more applied research. Although this has been a long-standing concern, the available evidence on this is not conclusive, despite some evidence of HEIs' increased inclination to undertake applied research.

\section{International sources of funding}

International funding also has important implications for the steering and performance of research. In the European context, supranational funding for research through the EU's Horizon 2020 programme is not only an important source of research funding, but it also shapes and "influences" national research agendas, notably through its emphasis on operational research funding directed towards the grand challenges. This in turn has an impact on the bottom-up orientation of research at HEIs. Similarly, the EU's Smart Specialisation Strategy provides an additional source of funding from EU structural funds that is used for research infrastructure and human resource development at the regional level. In smaller EU countries, this funding is a large source of HEI funding, representing $24 \%$ in the Czech Republic, for example [Kostic et al., 2016].

\section{Other, non-governmental research funding schemes}

Foundations, alumni, wealthy individuals, charitable trusts and crowdfunding are increasingly important and growing sources of research funding for HEIs. Philanthropic funding accounts for almost $30 \%$ of the research funding of leading research universities in the United States and represents more than US $\$ 4$ billion a year [Murray, 2012]. The United Kingdom is another example of where philanthropic funding represents a notable share of the revenue of HEIs. Some research universities in the United Kingdom earn almost $10 \%$ of their total income from philanthropic sources [Estermann, Pruvot, 2011]. Philanthropic funding is partially encouraged by the policy of the UK government to provide additional research funds to HEIs depending on their charity income; the charity support funding was approximately $£ 198$ million in 2015-2016 [HEFCE, 2011].

\section{Autonomy in financing}

The diversification of funding sources and channels might have a direct bearing on the autonomy of HEIs. Firstly, more diversified funding sources and channels of HEIs may imply that they are less dependent 
on a specific funding channel, particularly on government funding; which provides HEIs with a sense of increased autonomy in research and education. This kind of argument is often used to encourage HEIs to make efforts to diversify their funding sources. However, in a context where the diversification of funding sources is usually accompanied by an increase in competitive-based funding and contractual arrangements, the effects of funding diversification should be analysed using empirical evidence.

The more autonomous HEIs are in financing can potentially enhance the diversification of funding channels as HEIs try to enlarge their sources of funding. This aspect can raise an issue for policymakers about the degree of autonomy that should be granted to HEIs. Currently, the authority of HEIs to make important decisions on financing varies across countries. For example, universities in Italy, Portugal and the UK can decide the level of tuition fees under a ceiling, which is decided by governmental authorities, while the government sets the fixed amount of tuition fees in France, the Netherlands and Spain. Furthermore, autonomy in financing encompasses various issues concerning one's ability to retain a potential surplus from state funding, the ability to raise money on financial markets and the ownership and sale of real estate [Estermann et al., 2011].

\section{Place-based policies and HEIs: Challenges, obstacles and open questions}

In a place-based context, municipal governments must invest in the knowledge base of HEIs but they must also encourage cooperation between HEIs and the local ecosystem in order to encourage firm competitiveness and structural change through new firm growth. However, in many countries, higher education and research policy lacks an explicit territorial dimension. Academics and their universities are generally rewarded on the basis of the quality of their research activities or whether they collaborate with businesses, irrespectively of where companies are located. The lack of an explicit territorial dimension is often reflected by funding and incentive mechanisms defined by national agendas that generally provide little support for regional engagement. In some cases, there might be a lack of co-ordination at the government level: ministries or departments responsible for higher education and research might tend to promote a national or even international excellence agenda, at the same time the departments responsible for territorial development might encourage universities to maximise local knowledge spillovers.

An additional challenge in promoting regional engagement is the lack of appropriate and reliable metrics. The impact of regional engagement is difficult to measure. It is very challenging to measure how much HEIs have impacted the regional and local economic performance after the fact. Evaluation practices for research and education activities - instead - are much more well-established. For this reason, evaluations of HEIs often take these two missions into account and only partly consider the third mission or regional engagement.

Whether to expect most institutions to undertake all forms of academic activity including research, teaching and community service or to designate some as mainly teaching-only institutions and to concentrate research in a few world-class research-intensive institutions is an open question. Depending on the region, the critical mass of researchers, the economic specialisation as well as other factors, different HEIs' profiles and strengths may benefit the local ecosystem in different ways. In addition, on the local demand side, even if a leading university is located in a particular region, there may be limited absorptive capacity in local enterprises, especially SMEs or the branches of multinationals that do not perform local in-house R\&D activities [Goddard, Puukka, 2008].

To overcome some of the challenges described above, some countries have introduced "third-mission"related activities in the performance contracts between the state and universities. In Austria, 15 out of 22 public universities agreed to introduce elements of place-based innovation in their three-year performance contracts. This strengthened the role that universities played in the design of Smart Specialisation Strategies in Austria [OECD, 2014].

Boundary-spanning organisations such as "technology transfer offices" and "research and development units" within universities themselves have often been encouraged and supported by regional and national policy initiatives. Regional governments, in particular, have adopted many initiatives to establish "intermediary bodies" to act as a catalyst between universities and businesses to incentivise their collaboration. The European Institute of Technology (EIT), which is promoted by the European Commission, is just one example of such an initiative at the European level.

Capacity building in regional innovation systems requires not only the research and talent in universities (generative capacity), but also an absorptive capacity in the private sector and clusters; a collaborative capacity in networks, associations and joint facilities; and a leadership capacity from boundary-spanning organisations with a guiding vision. Improving innovation systems at the local level can be hampered by, among other things, a lack of political leadership on the part of the local government, low demand from the private sector, narrowly focused academic research and teaching at HEIs, and a lack of "boundaryspanning" organisations. For these reasons, traditional place-based policy approaches have largely underestimated the educational role of universities and other HEIs in strengthening regional innovation ecosystems and fostering structural change [OECD, 2015].

Given the large heterogeneity of regional innovation ecosystems and the importance of place characteristics for the innovation process (reviewed in the first section), place-based innovation policies in support of 
the KT seem well-warranted. The diversity of regions, their various levels of economic development, and industrial specialisation all call for tailored approaches.

\section{Third mission activities}

Knowledge exchange and community engagement are long-standing characteristics of HEIs in most OECD countries. However, during the move towards increased autonomy and accountability for most countries' HEIs, many states have acted to strengthen and formalise the social and knowledge transfer role of HEIs. In Sweden, for example, the third mission is officially recognised as a mission of HEIs in the Higher Education Act. Third mission policies therefore partially represent a more active state role in reorienting higher education towards social concerns and innovation. Some countries have dedicated innovation funding schemes to encourage knowledge exchange activities such as interaction with smalland medium-sized enterprises (SMEs). Some OECD countries have also made efforts to measure and record collaboration and dissemination activities. Such policies can also be seen as a response to the "innovation paradox" and concerns in many countries that high-quality research has not been translated into innovation performance [IPP, 2015a].

As a result of increased policy attention, these activities, or at least their measurement, may have become more widespread. For example, Marginson and Considine [Marginson, Considine, 2000] remark upon the increase in community service and engagement among Australian universities since the 1990s. However, another reason for the increase may be that certain collaboration activities provide an important revenue stream for HEIs. Income from contract research, for example, has become an important source of income for a number of HEIs [OECD, 2008]. Some countries have attempted to increase the capacity of HEIs to engage in knowledge exchange activities by providing dedicated funding (see, for example, the Innovation Policy Review of Sweden, [OECD, 2013]). A detailed evaluation of knowledge exchange funding for HEIs in England found that the policy has generated significant additional knowledge exchange income for institutions, as well as strengthened aspects of the link between teaching, research and knowledge exchange [HEFCE, 2009].

\section{Policy contradictions and open questions}

Many governments are interested in enhancing HEIs' contributions to the innovative process, economic growth and social development. Rather than being seen as separate missions, education, research and innovation should be seen as part of an overall system encompassing a range of economic and social objectives. Research policies, education policies and innovation policies can be mutually reinforcing, but country diversity shows that there is no single model for alignment. Policies designed to promote innovation directly can have adverse effects on those that promote innovation indirectly. In the context of the knowledge triangle, these interrelationships are an important consideration for policy and governance mechanisms concerning HEIs.

A key issue from the perspective of the knowledge triangle is the potential complementarity or trade-off between the different missions of HEIs, and the implications for innovation. Some of the broad changes affecting STI policy and HEIs can have a number of effects on these relationships. The following section sets out some potential and tentative implications.

\section{Tensions between universities and PROs}

In many OECD countries, the focus on universities as hubs of knowledge creation, entrepreneurship and innovation has challenged the traditional division of labour between universities and government labs or institutes that fall under the broad heading of "public research organisations". PROs often undertake longer term research that goes beyond the 3- or 5-year funding cycles that are typical for research programmes at universities. In some cases, institutes have been merged with universities (e.g., the Rosline Institute at the University of Edinburgh). While the trend of transferring labs to universities helps in retaining knowledge creation capacity, this can also create tensions between academic departments which must seek short-term competitive funding and centres and institutes which have ring-fenced funding.

\section{Potential trade-offs in knowledge production and diffusion}

The increased commercialisation-based and profit-seeking attitude associated with financial autonomy may have competing effects on an HEI's research activities. For instance, a push for commercialisation could impinge on an HEI's willingness to extend informal expertise. Faculty that could earn money from consulting activities might also have fewer incentives to engage in community outreach. The formalisation of knowledge transfer activities creates benefits but also problems for companies. For most HEIs, informal and formal linkages with industry, as well as student and staff mobility, are the most important sources of commercialisation and knowledge transfer [OECD, 2011]. Increased industry-HEI collaboration and the formalisation of knowledge transfer raises the potential risk of negative effects on basic research spending, scientific inquiry for its own sake and the free dissemination of discoveries would decline [Mendoza, 2015]. More speculatively, the incentives created by research funding schemes oriented towards academic excellence could potentially discourage activities linked to the third mission 
unless there were strong monetary or altruistic incentives to perform these activities in place. At the very least, faculty are limited in the amount of time they can devote to third mission activities insofar as career advancement depends more on publishing and teaching. At the same time, a more competitive and market-driven environment may encourage HEIs to build linkages with external partners as a potential source of research funding and income. Linkages with industrial, government and community partners can be a source of ideas for researchers.

\section{Relationship between education and research}

Debates over the relationship between research and teaching are long-running. There are reasons for teaching and research to be complementary: knowledge of up-to-date research can improve the quality of education and the relevance of investments in human capital, while the movement of students into the workplace allows knowledge from research to be disseminated more effectively. Feedback to research universities from students and prospective employers can help maintain the social relevance of research. Yet the long-running increase in the rewards to research relative to teaching is often argued to have weakened the relationship between the two. Empirical evidence at the student/academic level, predominantly in the United States, tends to find no or limited evidence for a positive relationship between research productivity and teaching effectiveness as judged by students [Centra, 1983]. The researchintensive units that are most successful at winning competitive grants, such as medical schools, may not be responsible for extensive education and training. In addition, if research increases in complexity over time it may become less closely connected to education. The nature of the relationship between education and research is likely to vary by the fields of science and education.

\section{Relationship between education and the third mission}

Similarly, a number of factors could affect the relationship between third mission activities and education. Interactions between researchers and industry or the local community can help them relate their research and teaching to real-life problems. Vocational education colleges, in particular, may face the challenge of keep their programmes up-to-date with technology and innovation [Toner, Dalitz, 2012]. Thorn and Soo [Thorn, Soo, 2006] show how a "third-mission" orientation has had spillover effects on the advanced training activities of universities in Latin America (e.g., real-life problems in university courses and collaborative doctorate research projects). Education can affect innovation too: Thune and Børing [Thune, Børing, 2014] show that the industry placement of doctoral degrees is used by firms for a range of purposes including developing broader competencies, knowledge in core technological areas, R\&D competencies and innovation capabilities. However, here too there could be negative effects. One concern is that an outward-looking focus encourages HEIs to focus education and training on shortterm employer needs, and potentially become less well-aligned with the unpredictable skill needs of the future. The impact of industry-academia linkages on students requires more research [Mendoza, 2015]. The governance mechanisms associated with the formalisation of the third mission, such as performance agreements and new evaluation methods, may also have their own effects on teaching and training.

\section{Fragmented governance}

At the national level, policy co-ordination is important for organising and implementing the policies towards education, research and innovation. In many countries, policy co-ordination takes place through inter-ministerial councils or through more informal means such as strategy documents and white papers. At the regional level, economic development agencies also exert an influence on HEI activities. The corollary of greater autonomy is that the task of co-ordinating and integrating the multiple missions of universities falls on the institutions themselves. However, the silo model of funding and regulations for the different missions do not facilitate these tasks for institutions. This altogether places large expectations on universities to align their missions and create interactions between these different tasks [Benner, Tushmann, 2015]. This results in a dual and at times fragmented governance system whereby institutional choices are determined by internal governance structures (e.g., rectors, faculties and departments) that are only partly influenced by national policies (legislation, funding) or regional actors. Furthermore, governance mechanisms such as performance agreements and evaluation criteria may inadvertently include a bias towards one or another element of the knowledge triangle.

\section{Place-based and HEI ecosystems}

HEIs are important employers and service providers that are an integral and permanent part of most regional economies. In some regions, co-operation between universities and external partners has a long history and has been supported by existence of industrial and scientific infrastructure in the region (e.g., science and technology parks) as well as clusters and regional support structures to foster innovation. In others, this collaboration was promoted by (supra-) national or regional-level policies and by the availability of increased funding to foster research, innovation and knowledge transfer. The availability of public funding programmes aiming directly at the exploitation of research results and at closer linkages between universities and companies has also brought regional governments and HEIs closer together. However, while HEIs are increasingly engaging local stakeholders on university boards or for fund raising, the corollary is also important. Economic development agencies can arguably do more to engage HEIs in 
their public service delivery missions, economic development, urban planning or "smart city" initiatives [Meissner, 2015a,b; Schiavone, Simoni, 2016; De Grande et al., 2014]. The role of HEIs in the regions also depends on the relative power and motivation of the actors. In a government-pull model, entrepreneurial universities assist the development of existing industries and the creation of new industries in response to incentives from the government, such as budget funds. In an industry-pullmodel, universities respond to opportunities for cooperation with industry on specific problems.

\section{Conclusion}

Higher education institutions (HEIs) play a central role in the innovation systems of OECD countries. Much of the government funding that is channelled for education and research is performed by HEIs. Firm innovation increasingly relies on the science base that is generated at HEIs as evidenced by data on patent-science linkages and industry-university collaboration. HEIs are also major employers of researchers in OECD countries and provide services to local and national economies. In addition, HEIs provide many public goods to society from knowledge spillovers and well-trained graduates to scientific recommendations for policymakers as well as private goods such as consulting services, patented inventions and contract research. For these reasons, an understanding of how national policies and institutional practices can enhance the contributions of HEIs to society and the economy is critical.

In light of the decentralisation of the funding for HEIs in many countries and high competition for support for research projects, these institutions currently experience colossal pressure from the government and other stakeholders. In order to meet modern requirements as well as the demand for more inclusiveness and accessibility, higher education institutions must be reformed. Raising the social and economic significance of HEIs is a key point of national policy, which requires new approaches. Therefore government agencies in the OECD place great hope in the knowledge triangle concept, which aims at exploring ways to better align and integrate the research, education and innovation functions of HEIs via national policies and institutional activities. Traditionally, the linking of research to innovation has been encouraged by governments and industry. In addition, at HEIs with a Humboldtian tradition (e.g., in Germany, the US and Northern Europe) the linking of research to education has been well established since the $19^{\text {th }}$ century. However, this link continues to evolve as governments channel greater amounts of research funding to HEIs. In contrast, the links between education and innovation have been less a focus of national policymakers or institutional leaders until recently.

The novelty of the knowledge triangle framework is that it encourages mechanisms to link education to innovation via entrepreneurship, for example, or innovation to education and research, for example, by permitting professors of practice from industry to lecture at universities. The goal of knowledge triangletargeted policies is to generate qualitative and quantitative effects from these interactions that are greater than sum of the individual outputs of HEIs (e.g., academic articles, graduates or academic patents, local employment effects).

However, HEIs are diverse actors with diverse missions. The "optimal" structure of HEIs in relation to innovation is likely to vary across countries. It follows that there is no single model of HEIs or of the knowledge triangle. A range of different types of HEIs can contribute to innovation via their education, research and other activities, in conjunction with other actors. For example, while leading universities may excel in the number of highly cited academic articles and academic patenting, small teaching-only institutions can also play an important role in developing the technical, creative and managerial skills that contribute to innovation in the surrounding regional economy.

Yet, despite the diversity of HEIs, data shows that education, research and innovation activities at HEIs are concentrated within a few large institutions in OECD countries. Concentration may reflect a combination of historical factors, size-scale factors, but also government policies, such as performancebased contracts and increases in research funding relative to education, etc. New institutional policies related to new public management ethos that raise institutional profiles or recruit "star" faculty to attract additional funding for students, research and business collaboration would strengthen competitiveness.

The conclusion is that there is no single model of universities and the knowledge triangle. This is due to the country-specific peculiarities of educational systems, diversity within HEIs and the functions they perform, as well as the specifics of regional ecosystems. Accordingly, the key to the efficiency of the knowledge triangle tools is their place-based adjustment. In order to achieve a tangible contribution by universities to the development of regional and local innovation, it is necessary to ensure complementarities and balance between their missions. 


\section{References}

Abbott M., Doucouliagos C. (2009) Competition and efficiency: Overseas students and technical efficiency in Australian and New Zealand universities. Education Economics, vol. 17, no 1, pp. 31-57.

Aghion P., Blundell R., Griffith R., Howitt P., Prantl S. (2009) The effects of entry on incumbent innovation and productivity. The Review of Economics and Statistics, vol. 91, no 1, pp. 20-32.

Aghion P., Dewatripont M., Stein J.C. (2008) Academic freedom, private sector focus, and the process of innovation. The RAND Journal of Economics, vol. 39, no 3, p. 617-635.

Aghion P., Howitt P.W. (2008) The Economics of Growth, Cambridge, MA: MIT Press.

Altbach P.G., Umakoshi T. (2004) Asian universities: Historical perspectives and contemporary challenges. Baltimore, MD: The Johns Hopkins University Press.

Benner M.J., Tushman M.L. (2015) Reflections on the 2013 Decade Award - "Exploitation, Exploration, and Process Management: The Productivity Dilemma Revisited” Ten Years Later. Academy of Management Review, vol. 40, no 4, pp. 497-514.

Bonaccorsi A. (2009) Division of academic labour is limited by the size of the market. Strategy and differentiation of European universities in doctoral education. Learning to compete in European universities (eds. M. McKelvey, M. Holmén), Cheltenham: Edward Elgar, pp. 90-127.

Bonaccorsi A. (ed.) (2014) Knowledge, Diversity and Performance in European Higher Education: A Changing Landscape, Cheltenham: Edward Elgar Publishing.

Bonaccorsi A., Colombo M.G., Guerini M., Rossi-Lamastra C. (2014) The impact of local and external university knowledge on the creation of knowledge-intensive firms: Evidence from the Italian case. Small Business Economics, vol. 43, no 2, pp. 261-287.

Borlaug B.S., Aanstad S., Solberg E., Thune T.M. (2016) The knowledge triangle in policy and institutional practices - The case of Norway (Report 2016:45), Oslo: Nordic Institute for Studies in Innovation, Research and Education (NIFU). Available at: https://brage.bibsys.no/xmlui/bitstream/handle/11250/2426878/NIFUreport2016-45.pdf, accessed 24.06.2017.

Bramwell A., Wolfe A.D. (2008) Universities and regional economic development: The entrepreneurial University of Waterloo. Research Policy, vol. 37, no 8, pp. 1175-1187.

Carayannis E.G., Meissner D., Edelkina A. (2015) Targeted innovation policy and practice intelligence (TIP2E): Concepts and implications for theory, policy and practice. The Journal of Technology Transfer. DOI: 10.1007/s10961-015-94338 (online, print version forthcoming). Available at: http://link.springer.com/article/10.1007\%2Fs10961-015-9433-8, accessed 12.10.2016.

Centra J.A. (1983) Research productivity and teaching effectiveness. Research in Higher Education, vol. 18, no 4, pp. 379-389.

Chavas J.-P., Barham B., Foltz J., Kim K. (2012) Analysis and decomposition of scope economics: R\&D at US research universities. Applied Economics, vol. 44, pp. 1387-1404.

Cohn E., Rhine S.L.W., Santos M.C. (1989) Institutions of Higher Education as Multi-Product Firms: Economies of Scale and Scope. The Review of Economics and Statistics, vol. 71, no 2, pp. 284-290.

Curi C., Daraio C., Llerena P. (2013) University technology transfer: How (in)efficient are French universities? Cambridge Journal of Economics, vol. 36, no 3, pp. 629-654.

Daraio C., Bonaccorsi A., Geuna A., Lepori B., Bach L., Bogetoft P., Cardoso M.F., Castro-Martinez E., Crespi G., Fernandez de Lucio I., Fried H., Garcia-Aracil A., Inzelt A., Jongbloed B., Kempkes G., Llerena P., Olivares M., Pohl C., Raty T., Rosa M.J., Sarrico C.S., Simar L., Stig Slipersaeter M., Teixeira Pedro N., van den Eeckaut P. (2011) The European university landscape: A micro characterization based on evidence from the Aquameth project. Research Policy, vol. 40, no 1, pp. 148-164.

Davies S., Hammack F.M. (2005) The channeling of student competition in higher education: Comparing Canada and the US. The Journal of Higher Education, vol. 76, no 1, pp. 89-106.

de Grande H., de Boyser K., Vandevelde K., van Rossem R. (2014) From Academia to Industry: Are Doctorate Holders Ready? Journal of the Knowledge Economy, vol. 5, no 3, pp. 538-561.

Estermann T., Nokkala T., Steinel, M. (2011) University autonomy in Europe II. The Scorecard, Brussels: European University Association.

Estermann T., Pruvot E.B. (2011) European universities diversifying income streams, Brussels: European University Association.

Etzkowitz H., Leydesdorff L. (2000) The dynamics of innovation: From National Systems and "Mode 2" to a Triple Helix of university-industry-government relations. Research Policy, vol. 29, pp. 109-123.

Fagerberg J., Godinho M.M. (2005) Innovation and catching-up. The Oxford Handbook of Innovation, New York: Oxford University Press, pp. 514-543.

Gackstatter S., Kotsemir M., Meissner D. (2014) Building an Innovation-Driven Economy - The Case of BRIC and GCC Countries. Foresight, vol. 16, no 4, pp. 293-308.

Geuna A., Muscio A. (2009) The governance of university knowledge transfer: A critical review of the literature. Minerva, vol. 47, no 1, pp. 93-114.

Goddard J., Puukka J. (2008) The Engagement of Higher Education Institutions in Regional Development: An Overview of the Opportunities and Challenges. Higher Education Management and Policy, vol. 20, no 2, pp. 11-41.

Gokhberg L., Meissner D., Sokolov A. (2016) Foresight: Turning Challenges into Opportunities // Deploying Foresight for Policy and Strategy Makers: Creating Opportunities through Public Policies and Corporate Strategies in Science, Technology and Innovation (eds. L. Gokhberg, D. Meissner, A. Sokolov), Heidelberg: Springer International Publishing, pp. 1-8.

Hartl J., Lassnigg L., Unger M. (2014) Higher education institutions and the knowledge triangle: Improving the interaction between education, research and innovation, Vienna: Institute for Advanced Studies.

HEFCE (2011) Summative evaluation of the CETL programme (final report by SWQ to HEFCE and the Northern Ireland Department for Employment and Learning), Bristol: Higher Education Funding Council for England. Available at: http://www.hefce.ac.uk/media/hefce/content/pubs/indirreports/2011/RE,1111,Eval,of,CETL/rd11_11.pdf, accessed 14.04.2016.

Hervás Soriano F., Mulatero F. (2010) Knowledge Policy in the EU: From the Lisbon Strategy to Europe 2020. Journal of the Knowledge Economy, vol. 1, pp. 289-302.

Hirvikoski T. (2013) The Knowledge Triangle Promoting Innovation and Multidimensional Learning. The Knowledge Triangle: Re-Inventing the Future (eds. P. Lappalainen, M. Markkula), Aalto: Aalto University, pp. 43-52. Available at: http://www.slideshare.net/DCSF/markku-markkula-parallel-1-the-knowledge-triangle-reinventing-the-future, accessed 23.06.2015. 
IPP (2015a) Actor brief: Higher education institutions (HEIs). Innovation Policy Platform. Available at: https:// innovationpolicyplatform.org/sites/default/files/rdf_imported_documents/ActorBriefHigherEducationInstitutes. pdf, accessed 18.01.2015.

IPP (2015b) Module on universities and public research institutes. Innovation Policy Platform. Available at: https:// innovationpolicyplatform.org/content/universities-and-public-research-institutes, accessed 18.01.2015.

Kostić M., Čadil V. (2016) Knowledge Triangle in the Czech Republic. TIP Case study, Paris: OECD (unpublished draft document).

Larédo P. (2007) Revisiting the third mission of universities: Toward a renewed categorization of university activities? Higher Education Policy, vol. 20, pp. 441-456.

Lepori B. (2008) Research in non-university higher education institutions. The case of the Swiss Universities of Applied Sciences. Higher Education, vol. 56, no 1, pp. 45-58.

Maassen P., Stensaker B. (2011) The Knowledge Triangle, European Higher Education, Policy Logics and Policy Implications. Higher Education, vol. 61, pp. 757-769.

Marginson S. (2006) Dynamics of national and global competition in higher education. Higher Education, vol. 52, pp. 1-39. DOI:10.1007/s10734-004-7649-X.

Marginson S., Considine M. (2000) The Enterprise University. Power, Governance and Reinvention in Australia, Cambridge: Cambridge University Press.

Markkula M. (2013) The Knowledge Triangle: Renewing the University Culture. The Knowledge Triangle: Re-Inventing the Future (eds. P. Lappalainen, M. Markkula), Aalto: Aalto University, pp. 11-33.

Meissner D. (2015a) Public-Private Partnership Models for Science, Technology, and Innovation Cooperation. Journal of the Knowledge Economy. DOI: 10.1007/s13132-015-0310-3 (online, print version forthcoming). Available at: http:// link.springer.com/article/10.1007/s13132-015-0310-3, accessed 12.10.2016.

Meissner D. (2015b) Developing "Green Thinking" Towards Sustainability. International Journal of Social Ecology and Sustainable Development, vol. 6, no 3, pp. 4-7.

Meissner D., Gokhberg L., Shmatko N. (2016) The Meaning of Doctorate Holders for Human Capital Development of Nations. The Science and Technology Labor Force: The Value of Doctorate Holders and Development of Professional Careers (eds. L. Auriol, L. Gokhberg, N. Shmatko), Heidelberg: Springer, pp. 343-350.

Mendoza P. (2015) Industry-Academia Linkages: Lessons from Empirical Studies and Recommendations for Future Inquiry. Higher Education: Handbook of Theory and Research, Heidelberg: Springer International Publishing, pp. 469-523.

Mowery D.C., Sampat B.N. (2005) Universities in national innovation systems. The Oxford Handbook of Innovation (eds. J. Fagerberg, D.C. Mowery), Oxford: Oxford University Press.

Murray F.E. (2012) Evaluating the Role of Science Philanthropy in American Research Universities (NBER Paper no w18146), Cambridge, MA: National Bureau of Economic Research.

Muzio D., Brock D.M., Suddaby R. (2013) Professions and institutional change: Towards an institutionalist sociology of the professions. Journal of Management Studies, vol. 50, no 5, pp. 699-721.

OECD (2008) Tertiary Education for the Knowledge Society (volumes 1 and 2), Paris: OECD.

OECD (2011) Regions and Innovation Policy. OECD Reviews of Regional Innovation, Paris: OECD. Available at: http:// dx.doi.org/10.1787/9789264097803-en, accessed 17.08.2016.

OECD (2011) TIP discussion paper on place-based policies and the knowledge triangle, Paris: OECD.

OECD (2013) OECD Reviews of Innovation Policy: Sweden 2012, Paris: OECD. Available at: http://dx.doi. org/10.1787/9789264184893-en, accessed 17.08.2016.

OECD (2014) Science, Technology and Industry Outlook 2014, Paris: OECD.

OECD (2015) Main Science and Technology Indicators, Paris: OECD.

OECD (2016) Science, Technology and Industry Outlook 2016, Paris: OECD.

Oosterbeek H., van Praag M., Ijsselstein A. (2010) The impact of entrepreneurship education on entrepreneurship skills and motivation. European Economic Review, vol. 54, pp. 442-454.

Pirttivaara M., Laitala P., Miikki L., Kalman A. (2013) Experiences in Implementing Knowledge Triangle: Cases. The Knowledge Triangle: Re-Inventing the Future (eds. P. Lappalainen, M. Markkula), Aalto: Aalto University, pp. 173-187.

Ponchek T.J. (2016) To Collaborate or Not to Collaborate? A Study of the Value of Innovation from a Sectoral Perspective. Journal of the Knowledge Economy, vol. 7, no 1, pp. 43-79.

Poti B., Reale E. (2007) Changing allocation models for public research funding: An empirical exploration based on project funding data. Science and Public Policy, vol. 34, no 6, pp. 417-430.

Proskuryakova L., Meissner D., Rudnik P. (2015) The use of technology platforms as a policy tool to address research challenges and technology transfer. The Journal of Technology Transfer (online, print version forthcoming). Available at: http://link.springer.com/article/10.1007/s10961-014-9373-8, accessed 12.10.2016.

Rhoades G. (1998) Managed professionals: Unionized faculty and restructuring academic labor, New York: SUNY Press.

Robertson J., Bond C. (2005) The research/teaching relation: A view from the edge. Higher Education, vol. 50, no 3, pp. 509-535.

Salmi J. (2007) Autonomy from the state vs. responsiveness to markets. Higher Education Policy, vol. 20, pp. 223-242.

Schiavone F., Simoni M.J. (2016) Prior Experience and Co-opetition in R\&D Programs. Journal of the Knowledge Economy, vol. 7, no 3, pp. 819-835.

Sjoer E., Norgaard B., Goosens M. (2011) Implementing Tailor-made CEE in Theory and in Practice. The Knowledge Triangle as a Conceptual Tool. Paper presented at the SEFI annual conference, 27.09-30.09.2011, Lisbon.

Sjoer E., Nørgaard B., Goossens M. (2013) Implementing Tailor-Made CEE in Theory and in Practice: The Knowledge Triangle as a Conceptual Tool. The Knowledge Triangle: Re-Inventing the Future (eds. P. Lappalainen, M. Markkula), Aalto: Aalto University, pp. 53-72.

Stam E., Romme A., Roso M., van den Toren J.P., van der Starre B.T. (2016) The Knowledge Triangle in the Netherlands: An Ecosystem Approach (draft case study for the OECD working party on innovation and technology policy), Paris: OECD (unpublished).

Thorn K., Soo M. (2006) Latin American universities and the third mission: Trends, challenges and policy options, Washington, D.C.: World Bank Publications.

Thune T., Børing P. (2015) Industry PhD Schemes: Developing Innovation Competencies in Firms? Journal of the Knowledge Economy, vol. 6, no 2, pp. 385-401.

Toner P., Dalitz R. (2012) Vocational education and training: The terra incognita of innovation policy. Prometheus, vol. 30, no 4, pp. 411-426.

van Petegen W. (2013) Lifelong Learning Strategy Development. The Knowledge Triangle: Re-Inventing the Future (eds. P. Lappalainen, M. Markkula), Aalto: Aalto University, pp. 73-84.

Vargiu A. (2014) Indicators for the Evaluation of Public Engagement of Higher Education Institutions. Journal of the Knowledge Economy, vol. 5, no 3, pp. 562-584.

Wallis C. (2006) The multitasking generation. Time Magazine, vol. 167, no 13, pp. 48-55. 